\title{
A LINGUAGEM DA PROPAGANDA COMO FERRAMENTA PARA O ENSINO DE LEITURA
}

\section{THE LANGUAGE OF PROPAGANDA AS A TOOL ON TEACHING HOW TO READ}

Sayonara Abrantes Oliveira Uchoa

Mônica Mano Trindade Ferraz ${ }^{\mathrm{ii}}$

RESUMO: O presente artigo analisa a riqueza linguística do gênero textual propaganda como campo produtivo para o ensino de leitura, fundamentando-se em dois aspectos constitutivos e suas contribuições à cognição: a multimodalidade e as relações lexicais. O trabalho apresenta argumentos a favor de uma abordagem do ensino de leitura fundamentado numa visão interativa, através do qual o aluno vivencie, conscientemente, os fenômenos lexicais em consonância com os recursos multimodais mobilizados no texto para a construção dos sentidos, permitindo a este leitor perceber-se como coautor do processo. Pautando-nos em teorias de gênero textual, de leitura, nas reflexões sobre o texto publicitário, na multimodalidade e nas bases da Semântica Lexical, em Antunes (2009; 2012), Kleiman (1999; 2011), Marchuschi (2011), Carvalho (1996; 2014), Dionísio; Vasconcelos (2013), dentre outros, buscamos apresentar reflexões de como a integração dessas áreas do conhecimento linguístico podem convergir para o mesmo propósito: a compreensão do texto mediada pelo ato de ler. Enfim, as análises ora apresentadas contribuem para a reflexão sobre as questões pertinentes ao ensino de leitura ancoradas nas manifestações da multimodalidade e do léxico.

PALAVRAS-CHAVE: Propaganda. Multimodalidade. Léxico. Leitura.

ABSTRACT: This text analyzes the linguistic richness of the textual genre as a productive field for reading teaching, based on two constitutive aspects and their contributions to cognition: multimodality and lexical relations. The article presents arguments in favor of an approach to reading teaching based on an interactive vision, through which the student consciously experiences the lexical phenomena in line with the multimodal resources mobilized in the text for the construction of the senses, allowing this reader to perceive co-author of the proceedings. In this paper, we will focus on theories of textual genre, reading, reflections on advertising text, multimodality and the bases of Lexical Semantics in Antunes (2009, 2012), Marchuschi (2011), Carvalho (1996) , 2014), Dionysus; Vasconcelos (2013), among others, we seek to present reflections on how the integration of these areas of linguistic knowledge can converge for the same purpose: the comprehension of the text mediated by the act of reading. Finally, the analyzes presented here

\footnotetext{
Doutora em Linguística. Professora do Instituto Federal da Paraíba. E-mail: sayonara_abrantes@hotmail.com.

ii Doutora em Linguística. Professora da Universidade Federal da Paraíba. E-mail: monicatrin@hotmail.com.
} 
contribute to the reflection on issues related to reading teaching anchored in the manifestations of multimodality and lexicon.

KEYWORDS: Propaganda. Multimodality. Lexicon. Reading.

Submetido em: 05 nov. 2018

Aprovado em: 16 dez. 2018

\section{Introdução}

Este artigo analisa como a mobilização de fenômenos lexicais, em gêneros textuais marcados pela multimodalidade, a exemplo dos textos destinados à propaganda, promovem riqueza linguística constitutiva, caracterizando-se como um texto que abre possibilidades significativas para o desenvolvimento da leitura em sala de aula.

A presente discussão surgiu da percepção de que alunos do terceiro ano do Ensino Médio, embora já tenham vivenciado diversas experiências linguísticas através de gêneros textuais diferenciados, ainda apresentam sérias dificuldades de compreensão ao se depararem com gêneros textuais constituídos da relação entre o verbal e o não verbal.

Partimos do pressuposto de que os textos publicitários, embora tenham como objetivo a mobilização de aspectos voltados à atração do leitor/consumidor, ao convencimento, mobilizam fenômenos linguísticos e semióticos que passam a representar verdadeiros desafios de compreensão para esse leitor, o que, para nós, representa uma ferramenta muito significativa e produtiva para o desenvolvimento de capacidades de leitura.

Desse modo, objetivamos verificar como ocorre a mobilização do léxico em propagandas direcionadas aos adolescentes e, de que forma estas estruturas promovem o contato deste leitor com fenômenos linguísticos diversificados, riqueza linguística constitutiva da própria língua, caracterizandose como um texto que abre possibilidades significativas para o desenvolvimento da leitura em sala de aula.

Dentro dessa perspectiva, Carrascoza (2002) defende que o mais curioso do texto publicitário consiste na existência de entrecruzamento de informações 
advindas de dois universos: o semântico e o da formulação. Tanto um como outro estão direcionados pelas escolhas lexicais mobilizadas na formulação do texto e que funcionarão como caminhos para a construção dos sentidos, cuja leitura se dará na interação entre o autor, o texto e o leitor, fundamentando-se numa concepção interativa de leitura $(\mathrm{KOCH}, 2011)$.

Se, por um lado, o entrecruzamento de informações delimitado por Carrascoza (2002) atribui à propaganda uma atmosfera tão produtiva, por outro, requer do leitor a capacidade de mobilizar informações nos mais diversos níveis do texto, condição esta que gera para os alunos um verdadeiro empecilho interpretativo, de modo que muitos textos não mais representem um desafio, mas um verdadeiro enigma.

Atribuímos tal dificuldade ao fato de que, assim como defende Marcuschi (2011, p. 53), a compreensão textual consiste em um trabalho interativo, caracterizando-se como uma "[...] atividade de produção de sentidos colaborativa" e não somente a identificação de informações no texto, visto que grande parte dos aspectos a serem contemplados na compreensão não está presente na superficialidade do texto, pois ler envolve, além dos conhecimentos textuais, os contextuais.

Trata-se, pois, de um trabalho linguístico complexo que requer do leitor a capacidade de mobilizar conhecimentos para integrar a informação verbal e a não-verbal, inter-relação possível somente pelo entrecruzamento de elementos cotextuais e contextuais.

Seguindo esta visão, apresentaremos uma discussão sobre a constituição do texto caracterizado como propaganda, tendo como foco as relações lexicais e sua importância para o direcionamento da leitura.

Acreditamos, portanto, que o desenvolvimento de práticas de leitura fundamentadas na percepção de como esses fenômenos contribuem à construção do texto e da leitura caracterizam-se como práticas significativas capazes de levar o educando a exercitar a capacidade de conectar pensamentos, simular associações de ideias e de palavras.

Considerando as reflexões propostas, este artigo apresenta uma discussão teórica na primeira seção, analisando os entrecruzamentos entre as propagandas e a semântica lexical. Em seguida, na segunda seção, 
apresentamos a análise de textos selecionados a partir dos critérios que norteiam este estudo, promovendo, portanto, uma análise teórico-discursiva.

\section{Propaganda e léxico: um olhar sobre as campanhas educativas}

Inicialmente, é necessário estabelecer a caracterização de termos aqui utilizados, de modo a deixar claro o direcionamento que iremos adotar ao discutirmos as propagandas de conscientização.

Assumimos, neste estudo, a concepção de texto a partir de Beaugrande (1997, p. 10) que o define como "[...] um evento comunicativo em que convergem ações linguísticas, culturais, sociais e cognitivas".

Neste momento, fazemos um recorte das propagandas com base em dois critérios, ou seja, interessam-nos aquelas que foram produzidas para o período do Carnaval 2017 e destinadas ao público jovem.

A publicidade, segundo Carvalho (2014, p. 13), consiste em uma atividade apoiada em saberes diversos e que, dada a sua constituição "[...] impõe, nas linhas e entrelinhas, valores, mitos, ideais e outras elaborações simbólicas, utilizando os recursos próprios da língua que lhe serve de veículo, sejam eles fonéticos, léxico-semânticos ou morfossintáticos".

Além do propósito comunicativo, outro aspecto a considerar é o conceitual, no qual a propaganda ou publicidade são consideradas interdisciplinares e pertencentes a um mesmo universo: o da sedução.

No entanto, Carvalho (2014, p. 14) estabelece uma breve distinção e assim as define: "Propaganda é um termo abrangente, vem a propagar e inclui a propaganda política, a institucional, a ideológica e a comercial, sendo que esta última é considerada e nomeada como publicidade (institucional, de produtos ou de serviços)".

Pela abrangência do termo publicidade, neste trabalho, haverá o uso tanto de publicidade como de propaganda, embora seja necessário clarificar que constituirão o corpus somente as propagandas de cunho educativo.

A propaganda, em todas as suas formas de constituição, tornou-se 0 instrumento mais viável de divulgação de ideias, produtos, percepções políticas, enfim, representa o meio direto de acesso ao público. Por este delineamento, 
passou a ser instrumento permanente em campanhas voltadas à conscientização de grupos sociais acerca de comportamentos, doenças, situações de risco. Enfim, quando as entidades precisam "dar o recado" à população, é a propaganda o meio mais utilizado.

Sobre o propósito comunicativo deste tipo textual, Reboul (1975, p. 95) enfatiza.

\begin{abstract}
A essência da propaganda é ganhar as pessoas para uma ideia de forma tão sincera, com tal vitalidade, que no final, elas sucumbam a essa ideia completamente, de modo a nunca mais escaparem dela. A propaganda quer impregnar as pessoas com suas ideias. É caro que a propaganda tem um propósito. Contudo, este deve ser tão inteligente e virtuosamente escondido que aqueles quem venham a ser influenciados por tal propósito nem o percebam.
\end{abstract}

Refletindo sobre o exposto por Reboul (1975), paramos para analisar como este leitor, público alvo das propagandas, é influenciado sem, sequer, perceber. É neste momento que deixamos clara a importância destes textos para o desenvolvimento de práticas de leitura em sala de aula, pois, em sua constituição, são mobilizadas estratégias diversas que requerem do leitor a capacidade de formular hipóteses, refutá-las e reconstruí-las, num jogo interativo voltado à compreensão e à construção de suas conclusões acerca das temáticas trabalhadas em cada propaganda.

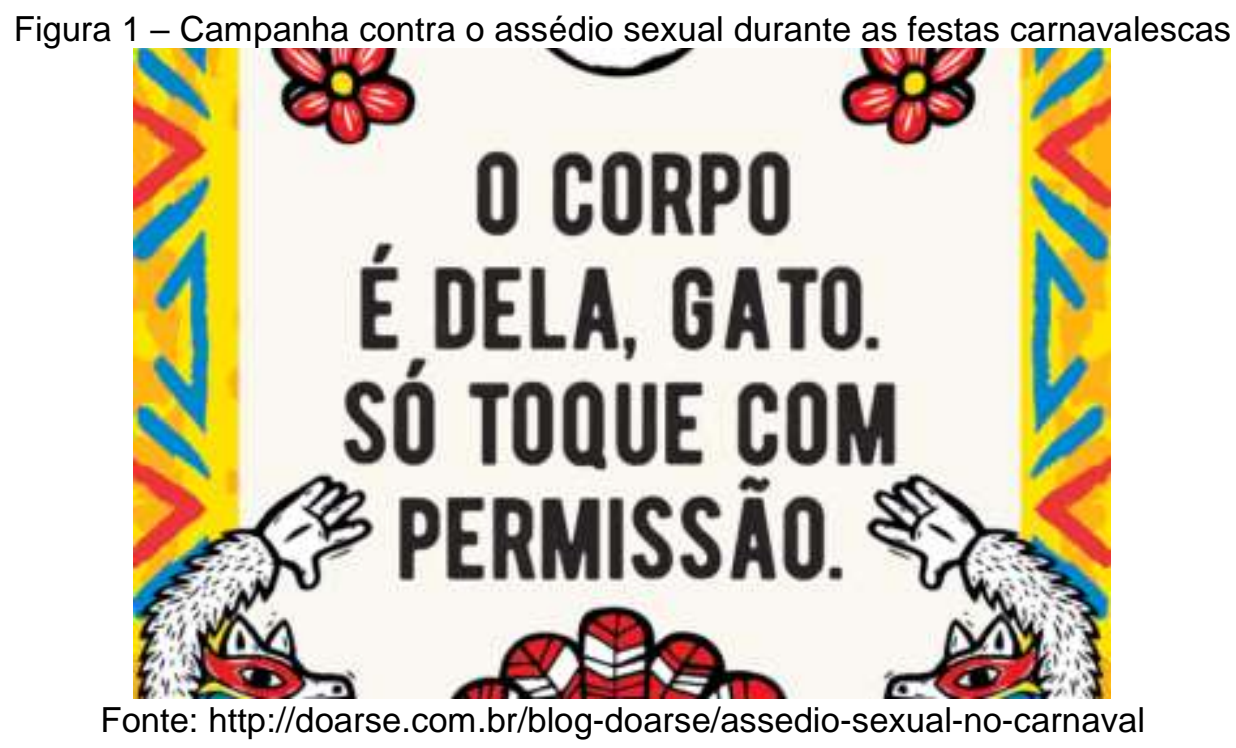


A publicidade acima faz parte de uma campanha destinada ao público jovem e que tem como foco o combate ao assédio sexual durante o carnaval 2017.

Por se tratar de uma campanha publicitária voltada ao esclarecimento e à conscientização acerca de situações constrangedoras, que podem ocorrer durante a festa de carnaval e que também configuram assédio, em sua construção são utilizados recursos voltados ao convencimento. Nossa afirmação pauta-se na reflexão de Carvalho (1996, p. 19) ao explicitar que os recursos linguísticos mobilizados na construção dos textos, sobretudo nos publicitários, "[...] têm o poder de influenciar e orientar as percepções e pensamento, ou seja, o modo de estar no mundo e de vivê-lo, podendo permitir ou vetar determinados conhecimentos e experiências".

O item lexical gato traz presente uma recorrência existente nestes textos, que é lançar mão da variação da língua, sobretudo de gírias que aproximem o leitor do texto, mantendo a sua atenção o maior tempo possível. Sandmann (2014, p. 48) explica que a propaganda se utiliza de escolhas lexicais que visam atrair o leitor, podendo até chocá-lo, como no caso das gírias, na tentativa de gerar empatia, chamar a atenção.

Ressaltamos que, embora esse recurso seja capaz de chamar a atenção ou gerar essa empatia pretendida, nada garante que atingirá o objetivo maior que é o convencimento acerca de uma dada ideia que está sendo propagada, visto que as variações sofrem influência de aspectos culturais e históricos e que, por tais características, geram significações que nem sempre são do conhecimento geral.

Dessa forma, o vocábulo gato, para um grupo de leitores, terá como referência um animal de estimação, enquanto que para outros, influenciados por uma série de fatores que determinam este conhecimento de mundo, será um homem de belas feições. O desencadeamento de cada uma destas interpretações é fruto das interpelações estabelecidas pelas variações regionais e impulsionadas pela faixa etária do grupo de leitores em contato com o texto.

Ademais, ao expressar "O corpo é dela, gato", o enunciado sugere uma relação direta entre os interlocutores do texto, levando-nos a pensar que aquele que o profere chama a atenção de outro, do sexo oposto, através do vocativo 
gato. Neste sentido, ocorre a percepção de um diálogo voltado à orientação, ou até um pedido por parte do locutor do texto, demonstrando certa familiaridade entre os interlocutores, fator que estabelece uma relação de proximidade entre eles, como sendo de um mesmo grupo social. Assim, fica evidente o cuidado com as escolhas lexicais, como também com as estruturas sintáticas denotadoras dessa proximidade entre os interlocutores, fazendo que se percebam como público alvo da campanha anunciada.

Para Sandmann (2014, p. 74), a função dessas escolhas "[...] é fazer um jogo com as palavras, é entreter o destinatário, desafiá-lo a entender a mensagem, prender sua atenção, enfim, e, em última análise, fazê-lo consumir o produto ou servir-se de um serviço".

Segundo Marcuschi (2011, p. 92), comportamentos como esses são possíveis devido ao fato de ser a língua "[...] semanticamente opaca e os textos podem produzir mais de um sentido. A língua permite a pluralidade de significações e as pessoas podem entender o que não foi pretendido pelo falante ou o autor do texto".

Por este direcionamento, no texto em ênfase, a possibilidade de uma mesma palavra poder apontar para dois referentes no mundo fornece ao leitor o direcionamento para a produção de hipóteses que são testadas com base em outros elementos internos e externos ao texto.

Percebemos que o texto publicitário dá ao leitor possibilidades de caminhar entre as tramas dos sentidos e gerar suas hipóteses. No entanto, é importante deixar claro que nem todas as possibilidades são aceitas visto que, pelo fato de a leitura caracterizar-se como uma atividade interativa, segundo Kleiman (2011, p. 39), “[...] tanto sujeito como texto delimitam o leque de possíveis leituras de um texto: não há abertura total, porque hipóteses de leitura devem ser verificadas".

Trata-se, pois, de uma estratégia bem comum à construção de textos publicitários lançar mão de escolhas lexicais consoantes ao universo do público alvo e das ideias pretendidas, abusando de ambiguidades, sinonímias, antonímias, enfim, no "vale tudo" do convencimento, a propaganda oferta aos docentes verdadeiras preciosidades textuais para o ensino de leitura. 
Outra situação será analisada considerando a figura 2, abaixo apresentada.

Figura 2 - Campanha contra o consumo excessivo de álcool durante o Carnaval

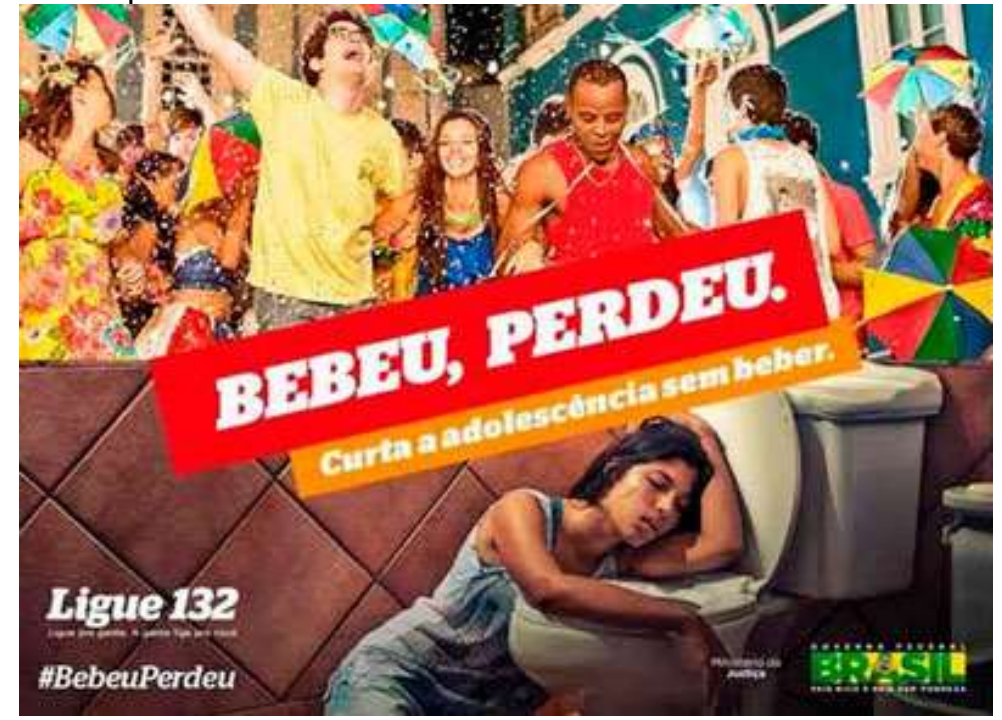

Fonte: http://www.justica.gov.br/noticias/conad

O texto 2 é construído através de dois fenômenos diferentes que, da maneira como foram organizados, funcionam como pistas para que o leitor se convença dos males causados pelo consumo do álcool, sobretudo na adolescência.

Num primeiro plano, é estabelecida uma relação entre o texto verbal e o não-verbal, direcionando o leitor à mobilização de conhecimentos de mundo voltados a dois contextos. O primeiro ocorre na relação entre o verbo beber com a imagem superior, em que o leitor estabelece uma sinonímia cultural entre o ato de beber e o de divertir-se que, por sua vez, se contrapõe, antonimicamente, ao verbo perder, gerando uma oposição semântica contextual.

Em outra visualização, é possível perceber a relação de causa e efeito, estabelecida entre beber e perdeu, somente possível pela organização sintática do período que leva o leitor a reconhecer a elipse da conjunção entre as orações como um elemento significativo de causa/efeito, marcada pela pausa sinalizada pelo uso da vírgula.

De acordo com Carvalho (2014), tais situações linguísticas nos textos voltados à publicidade ocorrem pelo fato de que 
Para construir linguisticamente esse discurso, haverá escolhas especiais nos itens lexicais e nas estruturas sintáticas. O léxico veiculador contará com denotações dentro do campo de significado que reforcem a construção dos estereótipos pretendidos e com conotações que possam ser inferidas com facilidade dentro do mesmo campo de significação. (CARVALHO, 2014, p. 24)

Percebemos, pelo exposto, que o texto publicitário, sobretudo aquele envolvido nas chamadas campanhas de conscientização, tem como objetivo convencer o leitor de uma verdade. No entanto, as escolhas linguísticas configuram pistas, através das quais, de acordo com Kleiman (1999, p. 47), “[...] o texto sugere, aproxima-se de um significado relevante, mas é o leitor quem deve construí-lo", cabe, portanto, ao leitor o preenchimento dos espaços vazios com conhecimentos de mundo por meio da ativação de inferências.

\section{Propagandas e o ensino de leitura}

Nossa análise assume a concepção interacional da língua, cujo foco centra-se na interação entre autor, texto e leitor e, através da qual, os sujeitos são compreendidos como agentes ativos que constroem os sentidos e por eles são construídos. Assim, fundamentamo-nos em Koch (2011) para direcionar a visão adotada para a leitura, uma vez que, segundo a autora.

[...] o sentido de um texto é construído na interação texto-sujeitos e não algo que preexista a essa interação. A leitura é, pois, uma atividade interativa altamente complexa de produção de sentidos, que se realiza evidentemente com base nos elementos linguísticos presentes na superfície textual e na sua forma de organização, mas requer a mobilização de um vasto conjunto de saberes no interior do evento comunicativo. (KOCH, 2011, p. 11).

As pesquisas de Uchôa (2018) chamam a atenção para o ensino de leitura promovido através de estratégias criadas com base na percepção dos fenômenos lexicais. Os resultados apontaram para a urgência em integrar à escola caminhos para o desenvolvimento de habilidades que permitam ao leitor o acesso às informações constantes nos mais diversos textos e, além disso, de orientar os leitores a aprenderem a gerar os sentidos.

Para melhor compreendermos a importância destes textos e a necessidade de levar os alunos a refletirem sobre a sua constituição, como um 
caminho para o desenvolvimento da leitura, tomaremos como exemplo o texto 3 , que faz parte de uma peça publicitária voltada à propagação do uso de preservativos desenvolvida pelo Ministério da Saúde (2017).

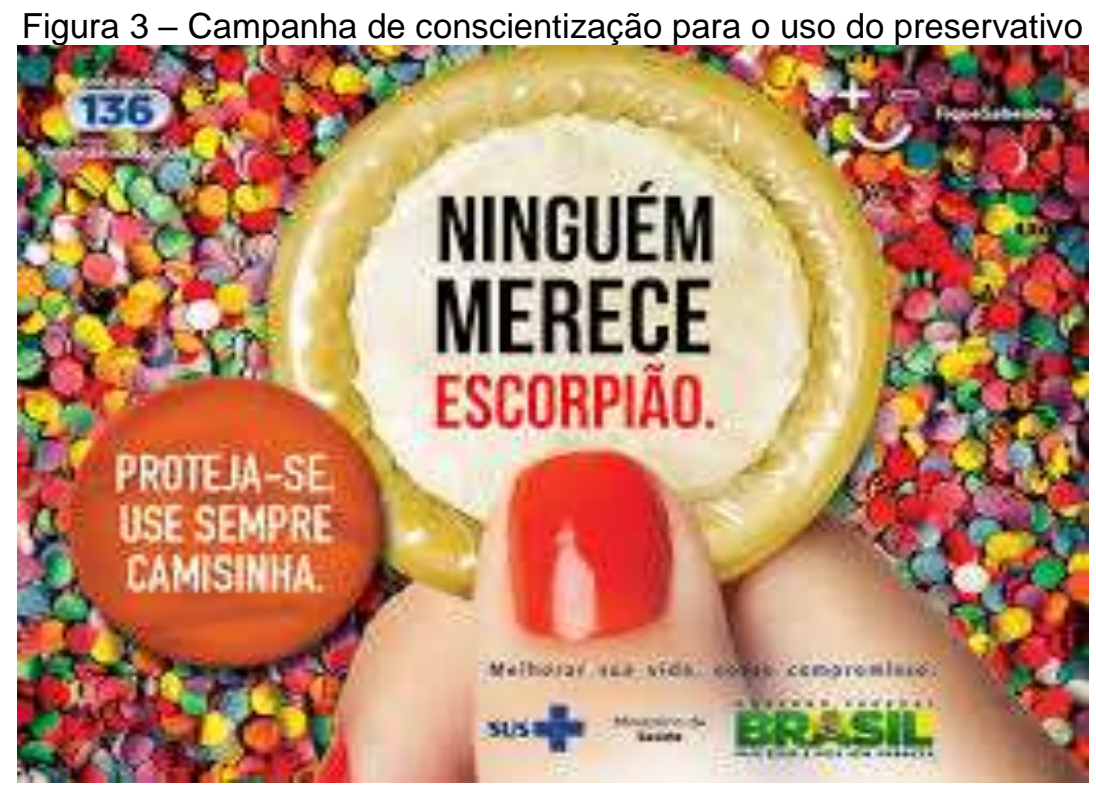

Fonte: http://portalarquivos.saude.gov.br/images/campanhas/Aids_Carnaval_2017/pecasgraficas/MS_Carnaval_Ad_Jornal_246x140.jpg

A primeira visualização dos textos nos dá uma breve dimensão dos artifícios utilizados pela indústria da propaganda para atender aos seus objetivos.

A ideia organizacional do texto é a associação do material linguístico a um domínio ideológico, estabelecendo um reforço de base positiva ou negativa, de modo a dar subsidio à ideia propagada.

No texto 3, o destaque é dado à expressão "Ninguém merece escorpião" na qual a palavra "escorpião" aparece grafada de vermelho para atrair a atenção imediata do leitor. Mas qual a relação entre o uso de preservativo e um escorpião? A construção do sentido é estabelecida por uma relação metafórica, visto que "[...] há uma transferência, quer dizer, com base na semelhança, um significante de signo passa a referir-se a outro objeto ou fato do nosso universo (SANDMANN, 2014, p. 85)". Assim, ocorre a associação dos males causados pelo escorpião, animal detentor de uma beleza exótica, cuja picada pode causar a morte, tal como o ato de praticar relações sexuais sem camisinha - ato que pode ser belo, prazeroso, mas que também pode matar. 
Há, ainda, um olhar pertinente acerca da ambiguidade construída pelo texto ao permitir a associação entre o termo "escorpião" com os signos do zodíaco, visto que, o fruto de uma gravidez indesejada seria um filho, cujo nascimento ocorreria em um período no qual a indicação astrológica determinaria a "casa" ocupada por esse signo. Assim, a ambiguidade consiste na referência do termo "escorpião", ora a um animal peçonhento, ora a uma criança nascida, astrologicamente, sob o signo representado por esse mesmo animal.

A complementação da informação é feita através do recurso não-verbal, associando a ideia de festa ao uso do preservativo, estabelecendo uma relação de pertencimento de um a outro.

Note-se que as escolhas lexicais são responsáveis por desencadear diversas associações através das quais será possível ao leitor estabelecer a compreensão do que está sendo propagado. Dessa forma, somente através desta capacidade de selecionar, localizar e estabelecer relações é que será possível um direcionamento à leitura da propaganda, ou seja, a compreensão depende da capacidade do público-alvo de retomar os conhecimentos linguísticos e extralinguísticos necessários à construção dos sentidos. Caso contrário, a propaganda somente chamará a atenção, não atendendo ao seu propósito de convencer. É preciso destacar, ainda, que o texto em ênfase dá uma pequena amostra de como a propaganda faz uso da capacidade criativa da língua em busca de seu objetivo maior: o convencimento.

Para Antunes (2012), a percepção da atribuição de novos sentidos às palavras na língua caracteriza-se como uma oportunidade de levar o aluno a compreender o constante movimento do léxico. Ressaltamos que essa concepção da língua deve ser vista na inserção em sua dinâmica cultural, percebendo como esse leitor visualiza os textos, numa relação permanente dos textos como eventos comunicativos.

Neste ínterim, compreendendo o papel do leitor como um construtor de sentidos (KOCH; ELIAS, 2011), ele deve ser capaz de fazer uso de estratégias como selecionar, antecipar, inferir e verificar de modo a conduzir os elementos cotextuais e contextuais às relações entre os sentidos e à compreensão. 
Com base neste papel, o leitor poderá deparar-se com o texto 3 e vivenciar os sentidos por ele propostos, percebendo a relação entre cada um e as situações sociais a que referem, compreendendo que "As palavras só ganham pleno significado no momento mesmo em que acontecem" (FARACO; TEZZA, 2003, p.47)

Ao discutir com o aluno os sentidos emanados do texto 3, o professor promoverá situações significativas de aprendizagem, haja vista que haverá a percepção de que as palavras apontam para diferentes sentidos e referentes que somente serão definidos a partir de ações inferenciais realizadas. Através destas relações, são eleitas as informações necessárias a serem trazidas do mundo para o texto para que ele faça sentido.

Para Cavalcante (2012)

\begin{abstract}
As inferências envolvem processos cognitivos que relacionam diversos sistemas de conhecimento, como o linguístico, o enciclopédico e o interacional. Esses conhecimentos entram em ação no momento em que articulamos as informações que se encontram na superfície textual (o contexto) com outras que se acham armazenadas em nossa memória, acumuladas ao longo de nossas diversas experiências. (CAVALCANTE, 2012, p. 31).
\end{abstract}

É por meio das inferências que o leitor é levado a desenvolver mecanismos de compreensão de como o léxico é mobilizado em cada situação de comunicação de forma diferenciada, pois todo ato comunicativo é único, visto que ocorre, também, em um contexto único.

Imaginar as palavras como rótulos é visualizar a língua como algo estável. Contrapondo-se a esta visão, Azeredo (2008) enfatiza que é necessário perceber as várias dimensões do uso da palavra em constante movimento. Destaca, ainda, que é preciso “[...] ir além da realidade já construída e aparente, buscando sob a superficialidade confortavelmente constante da fala de todos os dias, as pistas, as brechas, os atalhos que nos dão acesso ao território e objetos que aguçam nossa percepção [...]" (AZEREDO, 2008, p. 58).

Aguçar as percepções é um trabalho de leitura a ser desenvolvido pela escola e os textos publicitários são artefatos riquíssimos para levar o aluno a vivenciar, no ato comunicativo no qual se encontra inserido, a experiência de compreender os mecanismos lexicais. 
Nos textos aqui selecionados, os diferentes sentidos somente são ativados a partir da mobilização de expressões próprias do universo juvenil, a exemplo de "gato". Já em "bebeu, perdeu" e "ninguém merece", há o entrecruzamento de diferentes fenômenos, como o uso da frase feita e do jargão, com aspectos antonímicos, metafóricos além da recuperação de conhecimentos de mundo.

Enfim, cada situação apresentada na propaganda está inteiramente ligada com o universo dos leitores/alvo e, por tal, as escolhas lexicais realizadas para a construção do texto, baseado na possibilidade de uma mesma palavra ter vários sentidos ou formas de comportamento, levam o leitor a perceber essa dimensão criativa da língua.

A esse respeito, Cavalcante (2012) destaca:

\begin{abstract}
É a partir dessas deduções que preenchemos várias lacunas deixadas pelo contexto e fazemos antecipações, levantamos hipóteses sobre os sentidos do texto. Essas inferências dependem, por sua vez, de um conjunto de fatores, como grau de formalidade, o gênero textual, os conhecimentos dos interlocutores, a situação comunicativa específica em que se dá o texto. (CAVALCANTE, 2012, p. 31)
\end{abstract}

Compreender certos fenômenos da língua, mobilizados na construção do texto, ou seja, em contexto comunicativo, requer situações que levem o aluno a identificar e refletir sobre essas situações, de modo a estabelecer uma consciência linguística sobre certas regularidades e irregularidades da língua.

Assim, é papel da escola "[...] desvendar (quer dizer, 'tirar do escondido') os modos de funcionamento da língua; abrir esse universo para que as pessoas possam ver suas regularidades, suas estratégias e táticas de uso" (ANTUNES, 2009, p. 174).

A propaganda consiste, pois, em um texto cuja riqueza constitutiva, aliada às estratégias de leitura, possibilita experiências altamente significativas para a compreensão da língua.

\title{
Considerações finais
}

Nosso objetivo neste trabalho foi verificar como ocorre a mobilização do léxico em propagandas direcionadas aos adolescentes e, de que forma estas 
estruturas promovem riqueza linguística constitutiva, caracterizando-se como um texto que abre possibilidades significativas para o desenvolvimento da leitura em sala de aula.

Fundamentando-nos numa perspectiva de leitura enquanto atividade interativa, social, cultural e cognitiva, percebemos a necessidade de promover eventos pedagógicos em que os alunos sejam "apresentados" aos fenômenos lexicais mobilizados na construção dos sentidos nestes textos.

Em nossa visão, a compreensão de cada um destes fenômenos, no uso efetivo, no ato comunicativo efetivado nas propagandas que fazem parte do universo contextual, historicamente situado destes alunos, possibilita a construção de uma consciência linguística efetiva e, por tal, condições para o desenvolvimento da capacidade de ler e compreender.

\section{Referências}

ANTUNES, Irandé. Território das palavras: estudo do léxico em sala de aula. São Paulo: Parábola, 2012.

ANTUNES, Irandé. Língua, texto e ensino: outra escola possível. São Paulo: Parábola Editorial, 2009.

BEAUGRANDE, Robert A. New foundations for a science of text and discourse. Norwood: Ablex, 1997.

CARRASCOZA, João Anzanello. Redação publicitária. São Paulo: Futura, 2002.

CARVALHO, Nelly. O texto publicitário na sala de aula. São Paulo: Contexto, 2014.

CARVALHO, Nelly. Publicidade: a linguagem da sedução. São Paulo: Ática, 1996.

CAVALCANTE, Mônica Magalhães. Os sentidos do texto. São Paulo: Contexto, 2012.

FARACO, Carlos Alberto; TEZZA, Cristovão. Oficina de texto. Petrópolis: Vozes, 2003.

KLEIMAN, Angela. Texto e leitor: aspectos cognitivos da leitura. 6.ed.

Campinas: Pontes, 1999. 
KLEIMAN, Angela. Leitura: ensino e pesquisa. 4.ed.São Paulo: Pontes, 2011.

$\mathrm{KOCH}$, Ingedore Villaça; ELIAS, Vanda Maria. Ler e compreender os sentidos do texto. São Paulo: Contexto, 2011.

MARCHUSCHI, Luiz Antônio. Compreensão textual como trabalho criativo. 2011. Disponível em:

http://acervodigital.unesp.br/bitstream/123456789/40358/3/01d17t07.pdf.

OLIVEIRA, Luciano Amaral. Manual de semântica. Petrópolis: Vozes, 2008.

REBOUL, Olivier. O slogan. Trad. Inácio Assis da Silva. São Paulo: Cultrix, 1975.

SANDMANN, Antônio. A linguagem da propaganda. São Paulo: Contexto, 2014.

UCHOA, Sayonara Abrantes de Oliveira. Ativação de relações lexicais em propagandas: estratégia de leitura rumo à construção de habilidades de leitura. Tese (Doutorado em Linguística) - Universidade Federal da Paraíba. João Pessoa, 2018. 